\title{
F. W. Gehring: A Mathematical Biosketch
}

\author{
Peter Duren
}

Published online: 27 August 2014

(C) Springer-Verlag Berlin Heidelberg 2014

This issue of Computational Methods and Function Theory is dedicated to the memory of Frederick W. Gehring, an eminent mathematician who spent most of his career at the University of Michigan. Professor Gehring will be long remembered for his fundamental contributions to the theory of quasiconformal mappings, a field he developed in close coordination with colleagues in Finland.

Frederick William Gehring was born in Ann Arbor, Michigan on August 7, 1925. His family was of German origin; his great-grandfather Karl Ernst Gehring (18291893) had emigrated from Germany in 1847 and settled in Cleveland, Ohio, where he founded the Gehring Brewery. Fred's grandfather Frederick William Gehring (18591925) was treasurer of the brewery and co-founder of a bank in Cleveland. Fred's father Carl Ernest Gehring (1897-1966) loved music and was an amateur composer. He came to Ann Arbor to study engineering at the University of Michigan (UM), but soon switched to journalism and later worked for the Ann Arbor News as state news editor and music critic. Fred's mother Hester Reed Gehring (1898-1972) was the daughter of John Oren Reed (1856-1916), a physics professor at UM who later became Dean of the College. She and Carl met as undergraduates at UM. After the birth of their three children, she went on to complete a Ph.D. in German and served as a foreign language examiner for the UM Graduate School (Fig. 1).

Fred Gehring grew up in Ann Arbor and graduated from University High School in 1943. He was then admitted to MIT to study physics or engineering, but because there was a war on, he elected instead to enlist in the US Navy V-12 program, not knowing where he would be sent. By coincidence, the Navy sent him to Ann Arbor for a special year-round program in electrical engineering at UM. He graduated in 32 months with a double major in electrical engineering and mathematics. By that time the war was over, but the Navy sent him to sea for 4 months.

\footnotetext{
P. Duren $(\varangle)$

Department of Mathematics, University of Michigan, Ann Arbor, MI, USA

e-mail: duren@umich.edu
} 
Fig. 1 Fred as a small boy

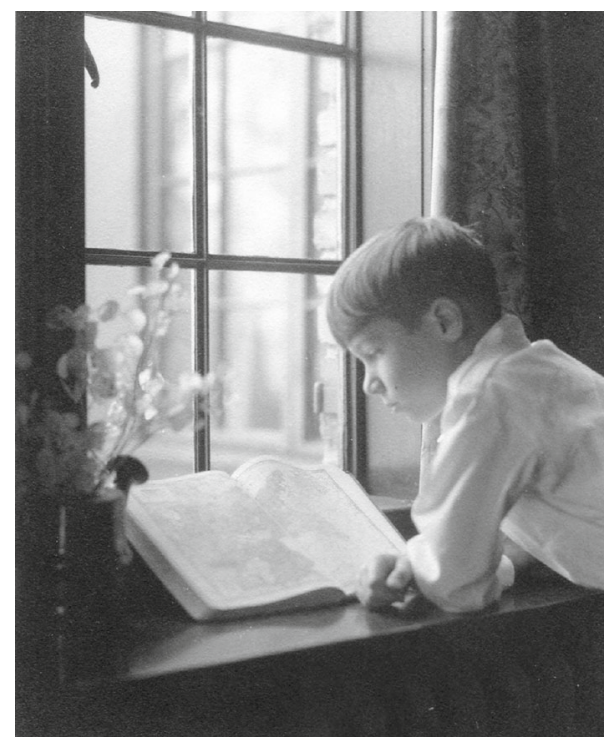

Upon his return, he re-enrolled at UM and decided, at the suggestion of Ruel Churchill, to concentrate on mathematics. After receiving an M.A. degree from UM in 1949, he went to the University of Cambridge (England) on a Fulbright Scholarship and remained to earn a Ph.D. in mathematics, taking courses from famous analysts such as J. E. Littlewood and A. S. Besicovitch while writing a thesis under the direction of J. C. Burkill.

At Cambridge, Fred met Lois Bigger, who had come from Iowa, also on a Fulbright Scholarship, to continue her study of microbiology. Both received their Ph.D. degrees from Cambridge in 1952-Fred in mathematics, Lois in biochemistry. When they returned to the US, Fred went to Harvard as a Benjamin Peirce Instructor, Lois to Yale on a Research Fellowship. They were married on August 29, 1953 in Lois's hometown of Mt. Vernon, Iowa (Fig. 2).

It was at Harvard that I first became acquainted with Fred. In the fall of 1954, as an undergraduate math major, I had the good fortune to attend his advanced calculus classes. There were two sections of that course; the other was taught by a well-known senior professor. As I recall, I began the course in the professor's section but found his lectures disorganized and confusing, so I quickly switched to Fred's section. It was like night and day. Fred's lectures were well prepared and beautifully clear, already organized in the outline format that became his trademark. He taught me a lot of mathematics that semester.

More important for Fred, however, was the acquaintance he made with Lars Ahlfors during his time at Harvard. As a student in England, Fred had specialized in real analysis, but the contact with Ahlfors made him increasingly interested in complex analysis. When Fred's position at Harvard came to an end in 1955, T. H. Hildebrandt managed to get him back to Ann Arbor, where he remained for the rest of his life. Then, in 1958, came a decisive event in Fred's mathematical career. Hoping to spend 

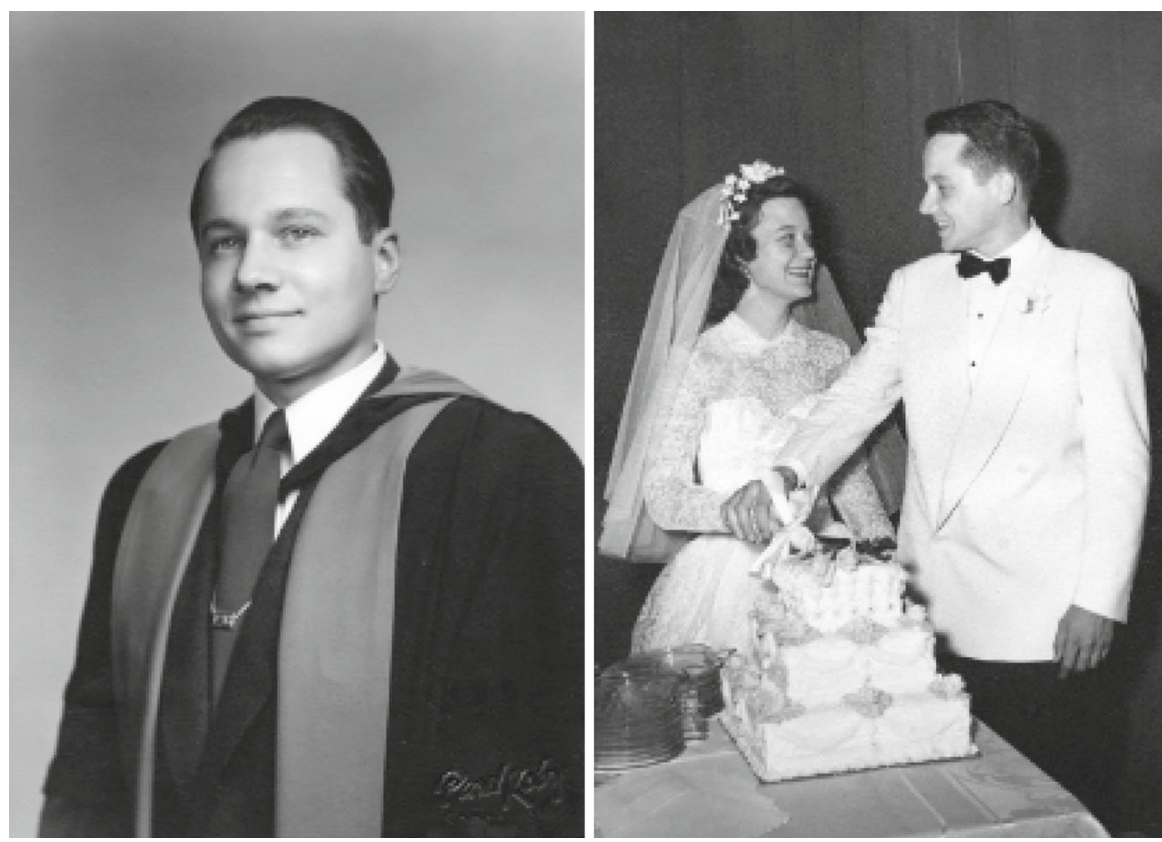

Fig. 2 Fred's graduation 1952 from Cambridge, Fred and Lois'wedding August 29, 1953

a year abroad, Fred applied for Fulbright, Guggenheim, and NSF fellowships and was awarded all three. His colleague Jack Lohwater had spent the year 1956-57 in Helsinki, where he saw that Olli Lehto and Kalle Virtanen, among others, were working on the theory of normal functions, a topic of interest to Fred. Encouraged also by Ahlfors, Fred decided to go to Helsinki. Lohwater put him in touch with Lehto, and Fred arranged to spend the year 1958-59 there.

Lehto [1] tells the story of Fred's year in Helsinki. When Fred arrived, he learned to his dismay that his Finnish hosts were no longer interested in meromorphic functions, but had been working on quasiconformal mappings. As the story goes, Fred asked what quasiconformal mappings were, and was told he would learn about them, as they were about to start a seminar on the topic, in Finnish! A daunting prospect, to say the least, but Fred responded to the challenge and was able to collaborate with Finnish colleagues in working out some analytic properties of quasiconformal mappings. Also, he and Lois both learned to speak Finnish that year, and Fred was soon giving seminar talks in the Finnish language. Their son Kalle was born in Helsinki and was named after Fred's father Carl and Kalle Virtanen. Their son Peter was born two years later in Ann Arbor (Figs. 3, 4).

In 1959-60, the Gehrings moved to Zürich, where Albert Pfluger had been working on quasiconformal mappings. Stimulated by discussions with Pfluger and a paper by Charles Loewner, Fred began to develop the theory of quasiconformal mappings in higher dimensions. In those two years abroad, Fred entered the new field of quasiconformal mappings and made professional contacts which would strongly influence the entire course of his career. In the years that followed, he was instrumental in devel- 


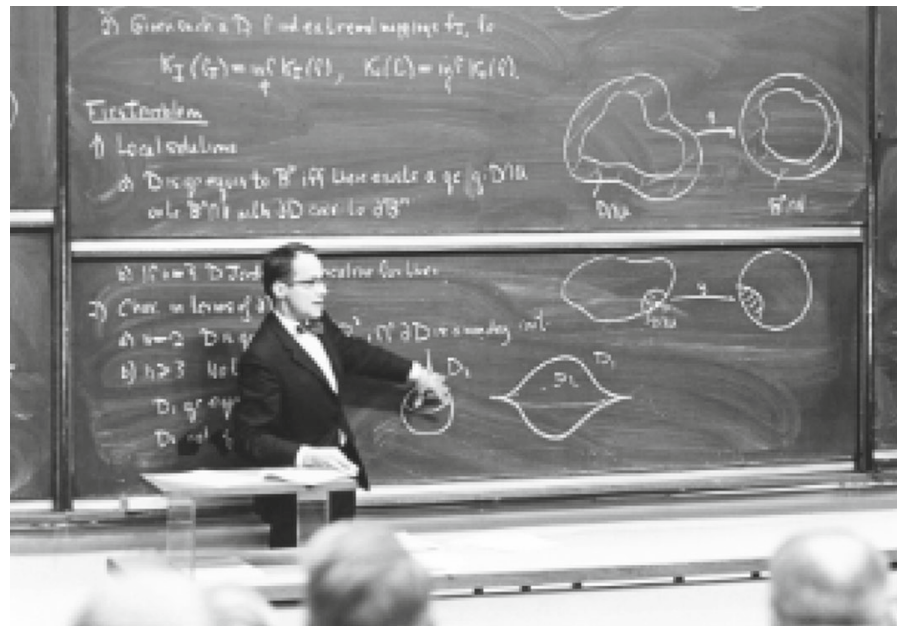

Fig. 3 Fred at 100th anniversary of Finnish Mathematical Society-1967

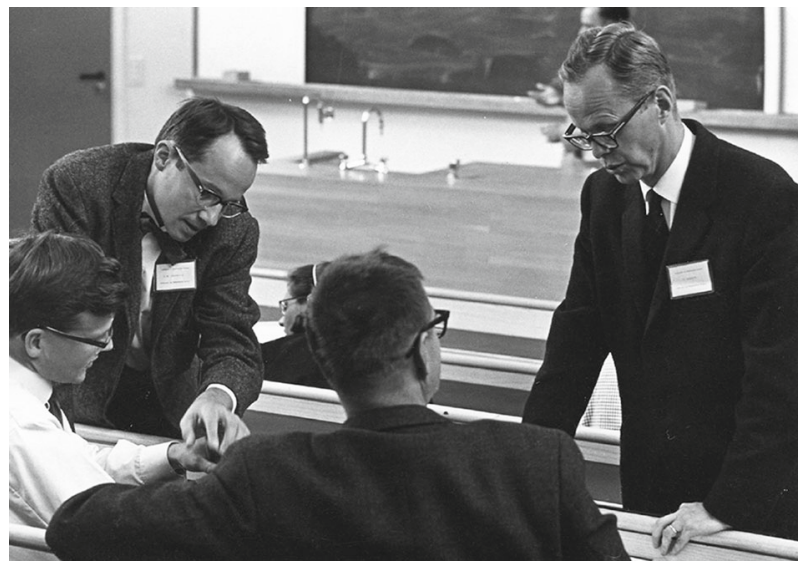

Fig. 4 Fred and Olli Letho (in conversation with Jussi Väsälä and Lalevi Suominen

oping the quasiconformal theory, often in collaboration with Finnish colleagues, and bringing it into the mainstream of mathematical analysis. In particular, he pioneered the important extension of the planar theory to n-dimensional Euclidean space, emphasizing new tools such as extremal length. His work [43] on the higher integrability of quasiconformal Jacobians lies at the foundation of that theory.

When he returned to Michigan in 1960, Fred began training students in quasiconformal mappings, and his first student graduated from UM in 1963. For the first few years after my arrival at UM in 1962, I shared an office with Fred and was able to witness his interactions with students, getting the benefit of his expertise and learning a thing or two about mentoring. In the course of his career, Fred directed 29 Ph.D. students, including two who received degrees from other institutions and one he took on after retirement. Fred and Lois took a personal interest in Fred's students and brought them 


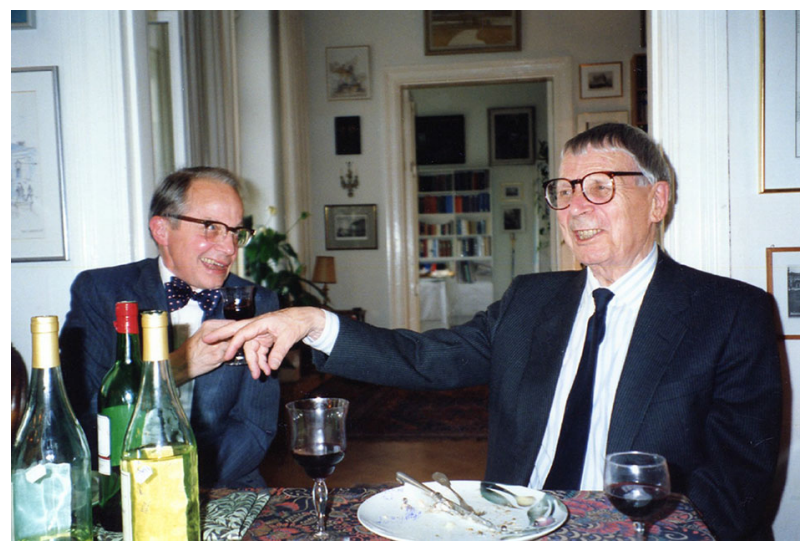

Fig. 5 Fred and Lars Ahlfors

into their family circle. Fred maintained contact with his former students for many years and continued to inspire them. Most of them have had active careers of teaching and research at academic institutions.

During the 1960s, Ann Arbor became known as a center for research in quasiconformal mappings. Finnish colleagues, as well as mathematicians from other parts of the world, began coming to Ann Arbor as visitors. Among the early visitors, for example, was Jussi Väisälä, with whom Fred wrote an important paper [29] on quasiconformal mappings in space. By the time of his retirement, Fred had sponsored UM visits by 42 foreign mathematicians (Fig. 5).

An important aspect of Fred's professional work was his extensive editorial service. At various times in his career, he worked on the Editorial Boards of 9 different research journals. He also served as Editor of book series for Van Nostrand (1963-70), North Holland (1970-94), and Springer-Verlag (1974-2003).

At the University of Michigan, Gehring was promoted to Professor in 1962. He served three terms as Chairman of the Mathematics Department, in 1973-75, 1977-80, and 1981-84. He was named to a collegiate chair in 1984, and became the T. H. Hildebrandt Distinguished University Professor in 1987. The University honored him with a Distinguished Faculty Achievement Award in 1981, the Henry Russel Lectureship in 1990, and a Sokol Faculty Award in 1994. An international conference on "Quasiconformal Mappings and Analysis" was held in Ann Arbor in August 1995 on the occasion of his 70th birthday. He retired in 1996.

Fred was invited three times to address the International Congress of Mathematicians, at Moscow in 1966, at Vancouver in 1974, and at Berkeley (a plenary lecture) in 1986. He was awarded honorary degrees from the University of Helsinki (1979), the University of Jyväskylä (1990), and the Norwegian University of Science and Technology (1997). In 1989, he was elected to the American Academy of Arts and Sciences and the National Academy of Sciences (USA). Other honors include an Alexander von Humboldt Award (1981-84), Commander of the Order of Finland's White Rose (19882012), and a Lars Onsager Professorship at the University of Trondheim (1995-96). He served for 19 years on various Committees of the American Mathematical Society, 
Fig. 6 Finnish White Rose medal

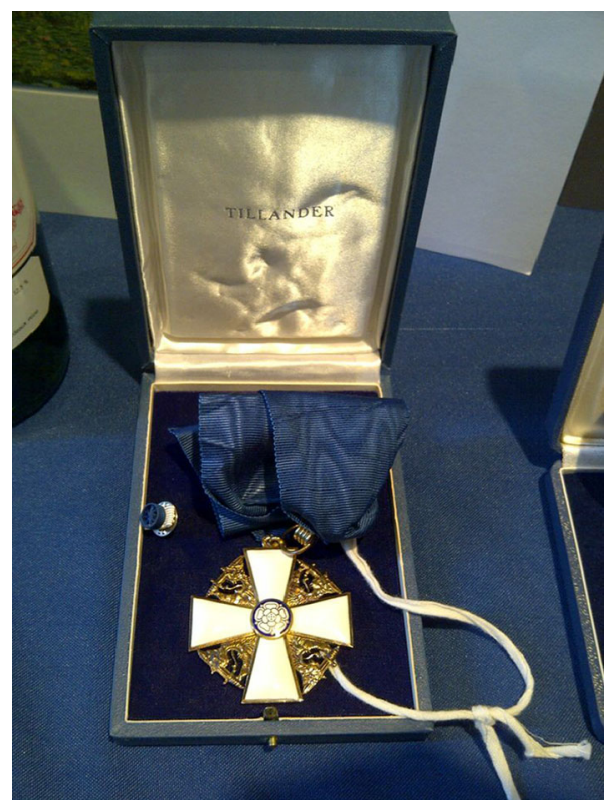

including three years on the Council, four years on the Executive Committee, and ten years on the Board of Trustees (Fig. 6).

In 2006, the AMS honored Gehring with a Steele Prize for Lifetime Achievement. The citation (Notices Amer. Math. Soc. 53 (2006), 468-469) says in part, "Largely because of Gehring's work, the theory of quasiconformal mappings has influenced many other parts of mathematics, including complex dynamics, function theory, partial differential equations, and topology. Higher dimensional quasiconformality is an essential ingredient of the Mostow rigidity theorem and of recent work of Donaldson and Sullivan on gauge theory and four-manifolds...Gehring's mathematics is characterized by its elegance and simplicity and by its emphasis on deceptively elementary questions which later become surprisingly significant".

Fred Gehring died in Ann Arbor on May 29, 2012 at age 86, after a long illness. His mathematical legacy includes about 130 research papers and two posthumously published books [5] and [2], written with former students. More detailed accounts of his mathematical contributions are given in the articles by Juha Heinonen and Bruce Palka [3] and Mario Bonk [4], as well as the article by Gaven Martin in the current volume.

\section{References}

1. Lehto, O.: Fred Gehring and Finnish Mathematics. In: Quasiconformal Mappings and Analysis: A Collection of Papers Honoring F. W. Gehring, Springer, New York, pp. 19-32 (1998)

2. Gehring, F.W., Martin, G., Palka, B.: The Higher Dimensional Theory of Quasiconformal Mappings, to appear in American Mathematical Society, Providence, RI 
3. Heinonen, J., Palka, B.: The Mathematics of F. W. Gehring. In: Quasiconformal Mappings and Analysis: A Collection of Papers Honoring F. W. Gehring, Springer, New York pp. 5-8 (1998)

4. Bonk, M.: Preface to special issue in honor of Frederick W. Gehring. Pure Appl. Math. Q. 7, 1-3 (2011)

5. Gehring, F.W., Hag, K.: Mathematical Surveys and Monographs. In: The Ubiquitous Quasidisk, vol 184, American Mathematical Society, Providence (2012) 